\title{
Chronic Obstructive Lung Disease in young: Alpha 1 anti trypsin deficiency
}

\author{
Subodh Sagar Dhakal*, Krishna Kumar Agrawal, Narendra Bhatta
}

Department of Internal Medicine, BPKIHS, Dharan, Nepal

\author{
DOI Name \\ http://dx.doi.org/10.3126/jaim.v3i2.14067

\section{Keywords} \\ COPD, Emphysema, Alpha 1 antitrypsin

\section{Citation} \\ Subodh Sagar Dhakal, Krishna Kumar Agrawal, \\ Narendra Bhatta. Chronic Obstructive Lung Disease \\ in young: Alpha 1 anti trypsin deficiency. Journal of \\ Advances in Internal Medicine 2014;03(01):65-67.
}

\begin{abstract}
Alpha-1 antitrypsin (AAT) deficiency is a clinically under recognized inherited disorder. The main clinical manifestations relate to three separate organs: the lung, the liver, and the skin. In the lung, severe deficiency of AAT predisposes to chronic obstructive pulmonary disease. We present a case of 34 years male with a history of recurrent chest infections in past and treated in the line of bronchial asthma but not relieved. He was admitted on 22nd May 2011 at BPKIHS. He presented with type 2 respiratory failure and had features of severe pulmonary arterial hypertension and left lower lobe pneumonia. The patient got improved with the treatment and is doing well on follow up. The diagnosis should be strongly suspected in patients with history suggestive of bronchial asthma and with obstructive features.
\end{abstract}

\section{INTRODUCTION}

Alpha 1 antitrypsin deficiency is a hereditary condition, first described in $1963 .{ }^{1}$ It results due to deficiency of neutrophil elastase. ${ }^{2}$ The deficiency of this protein can result in "genetic emphysema" primarily to the lower lobes of the lungs as well as liver disease, expressed as neonatal cholestasis that may progress to juvenile cirrhosis and slowly progressive liver disease in the adult. AAT deficiency is widely known as a disease of whites in Europe with individuals in that continent as well as their descendants in other parts of the world at the highest risk. ${ }^{3}$ Minimum protective plasma threshold of AAT is $11 \mu \mathrm{mol} / \mathrm{L}$ (corresponding to 50 to $80 \mathrm{mg} / \mathrm{dl}$, depending on the assay used), below which there is insufficient AAT to protect the lung, leading to an increased risk of developing emphysema. ${ }^{4}$ This condition is classified under the rare genetic adult lung diseases by the European respiratory society. This is probably the first case reported in adults from eastern Nepal.

\section{CASE PRESENTATION}

A 34 years old male teacher who never smoked presented with complaints of cough, shortness of breath and fever on $22^{\text {nd }}$ May 2011 at BPKIHS. The cough was present since he was six months old. It was progressive in nature, used to increase in night time and winter months and when exposed to dust or smoke. It used to be associated with shortness of breath on exertion. He was evaluated for this at a local health post where he was given cough syrups but not improved and told to have whooping cough. He was also taken to a district hospital where he was given some antibiotics and syrups but not improved. Due to his cough he could not play with his friends, was not

\footnotetext{
* Corresponding author Dr. Subodh Sagar Dhakal, Associate Professor Department of Internal Medicine, B. P. Koirala Institute Health Sciences Dharan, Nepal. subodhs_d@yahoo.com
} 
involve in household activities and needed to be protected from smoke. Till 15 years of age he used to have repeated chest infections and he did not seek further medical attention due to limitation of his resources. His family history is not suggestive of any similar illness. On examination there was peripheral cyanosis, clubbing, oxygen saturation was between $40-50 \%$ at room air and chest examination revealed diffuse wheeze with left sided infra-axillary and infra-scapular inspiratory crackles and pansystolic murmur in tricuspid area.

His investigations showed a hematocrit of $63.6 \%$. The chest X-ray (figure 1) showed hyperinflated lungs and prominent pulmonary artery.

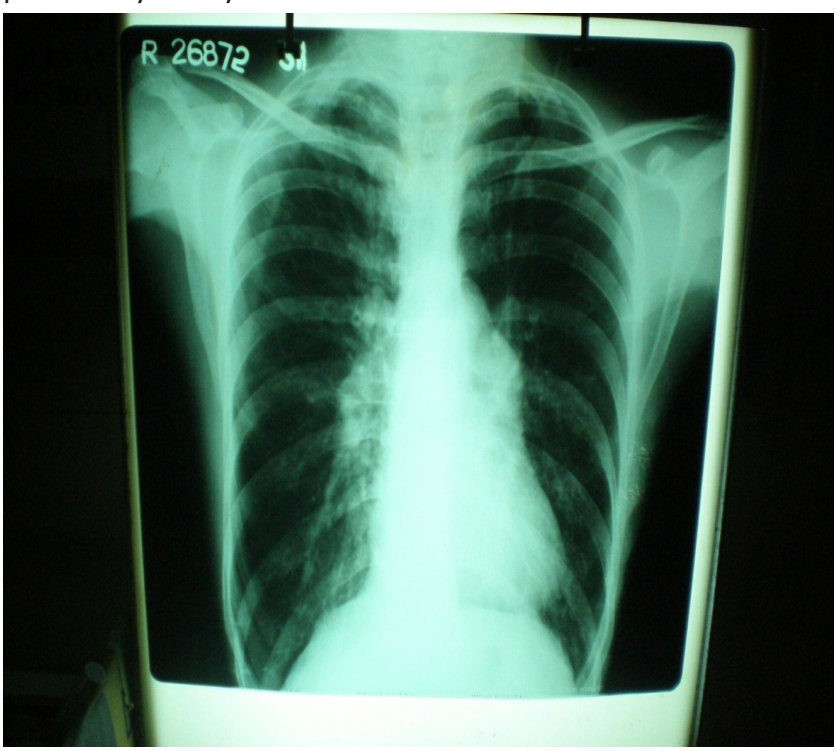

Figure 1: Chest $X$ ray PA view

ECG showed $\mathrm{P}$ pulmonale and Echocardiography (figure 2) showed severe tricuspid regurgitation with a right ventricular systolic pressure of $59.1 \mathrm{mmHg}$ and dilated right atrium and ventricle.
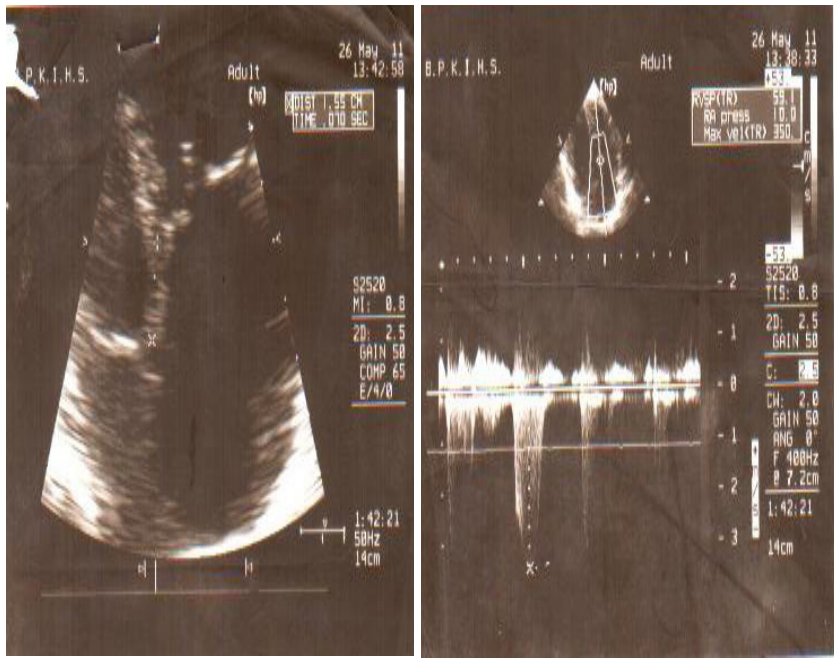

Figure 2: Echocardiography

The serum alpha 1 antitrypsin level was $56 \mathrm{mg} / \mathrm{dl}$ (84-163mg/ dl) by the nephelometry method. Ultrasonography of abdomen showed fatty liver. His contrast enhanced CT scan of chest (figure 3) reported hyperinflated and emphysematous bilateral lung field with bullae in bilateral upper and right lower lobe.

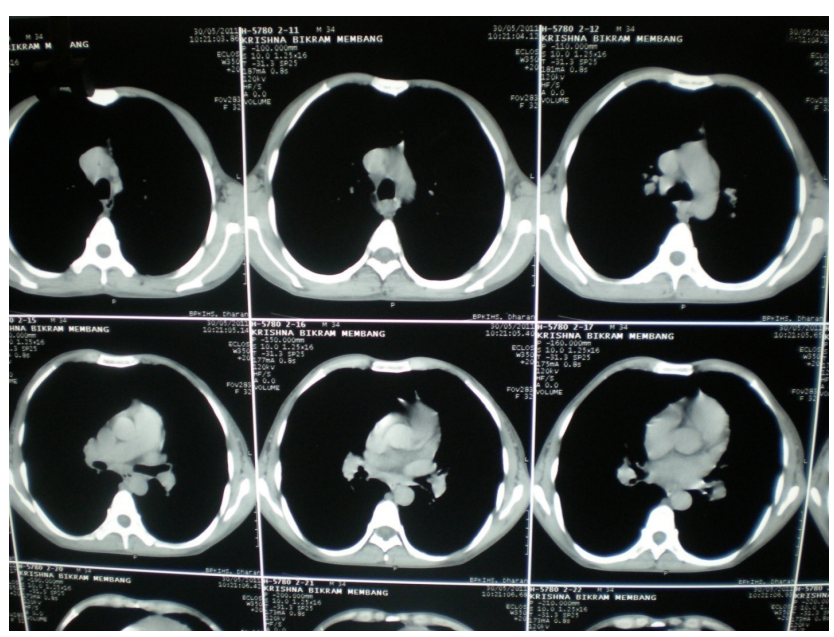

Figure 3: Contrast enhanced CT scan of chest

Fibrotic changes in bilateral upper lobes along with cystic changes and pulmonary infiltrates in left upper lobe with minimal pleural thickening in bilateral upper lobe regions. The pulmonary function test showed obstructive pattern and the reversibility test was negative.

He had therapeutic phlebotomy and managed with oxygen along with salbutamol nebulisation and received broad spectrum antibiotics. He was started on sildenafil. He improved and was discharged on domiciliary oxygen and preventive vaccination for influenza and pneumococcal was advised. On follow up is doing well.

\section{DISCUSSION}

Alpha 1 antitrypsin deficiency is commonly considered to be rare but estimates suggest that the disease is underrecognized. Worldwide, it is estimated that more than 3 million people have allele combinations associated with severe deficiency. ${ }^{2,3}$ It is clinically characterised by liver disease and early-onset emphysema. Although alpha1 antitrypsin is mainly produced in the liver, its main function is to protect the lung against proteolytic damage from neutrophil elastase. Emphysema in AAT deficiency is thought to result from an imbalance between neutrophil elastase in the lung, which destroys elastin, and the elastase inhibitor AAT, which protects against proteolytic degradation of elastin. The pathogenesis of the liver disease is quite different. ${ }^{5}$

Genetic epidemiological surveys of alpha 1 antitrypsin deficiency revealed that there were no genetic association with the AAT genes in Nepal. ${ }^{3}$ Pulmonary emphysema of the 
panacinar type is the most prevalent clinical correlate of this deficiency and is the major cause of disability and death. The second most frequent clinical complication is liver disease, usually presenting in infancy as cholestasis, which usually resolves by adolescence. ${ }^{1}$ However, the most recent data indicate that cirrhosis and carcinoma of the liver affect about $30-40 \%$ of patients with AAT deficiency over the age of 50 years and are a significant cause of death in nonsmoking individuals with the $\mathrm{PI}$ *ZZ phenotype. ${ }^{1}$

It has been postulated that there is protective threshold level of $11 \mathrm{micrmol} / \mathrm{l}$ which corresponds to $80 \mathrm{mg} / \mathrm{dl}$ if measured by radial immunediffusion and to $50 \mathrm{mg} / \mathrm{dl}$ if measured by nephelometry in patients with heterozygote phenotypes of AAT. In our case the nephelometric method was used which is a more recent test. ${ }^{1}$ In a study on the patients with AAT deficiency it was found that the cumulative probability of survival significantly shortened lifespan with a mean survival of $16 \%$ at $60 \mathrm{yr}$ of age compared with $85 \%$ for normal persons. ${ }^{6}$ The genetic phenotyping of the patient could not be done due to lack of facilities but we can theoretically argue on the basis of the clinical picture of emphysema, pulmonary arterial hypertension and the nephelometric assay of AAT levels that the patient is $\mathrm{PI} * \mathrm{Z}$ phenotype (i.e. homozygous $\mathrm{PI}$ ZZZ). ${ }^{4}$

Cigarette smoking increases the risk of developing fixed airflow obstruction and can markedly accelerate the onset of dyspnea by as much as 19 years. ${ }^{7}$ It is recognized that non smokers with the homozygous $Z$ phenotype have a remarkably delayed onset of symptoms and some may have an almost normal life span. The diagnosis of severe AAT deficiency is confirmed by demonstrating a serum level below 50 to $80 \mathrm{mg} / \mathrm{dL}(11 \mu \mathrm{mol} / \mathrm{L})$ in combination with a severe deficient genotype, generally determined by isoelectric focusing. ${ }^{1}$ The indications for testing for severe AAT deficiency.

Table 1: showing indications for testing for severe alpha 1

\section{REFERENCES}

1. American Thoracic Society/European Respiratory Society Statement: Standards for the diagnosis and management of individuals with Alpha-1 Antitrypsin deficiency. American journal of respiratory and critical care medicine 2003; 168:820-900.

2. Stoller JK, Sandhaus RA, Turino G, Dickson R, Rodgers $\mathrm{K}$, Strange C. Delay in diagnosis of alpha1-antitrypsin deficiency: a continuing problem. Chest 2005; 128(4):1989-1994.

3. Serres FJ. Worldwide racial and ethnic distribution of alpha 1-antitrypsin deficiency. Chest 2002; 122:18181829.

4. DeMeo DL, Silverman EK. Genetic aspects of alpha (1)-antitrypsin deficiency: phenotypes and genetic antitrypsin deficiency.

\begin{tabular}{l}
\hline $\begin{array}{l}\text { Emphysema in a young individual (i.e. less than or equal to } \\
45 \text { years) }\end{array}$ \\
\hline Emphysema in a nonsmoker or minimal smoker \\
\hline $\begin{array}{l}\text { Emphysema characterized by predominant basilar changes } \\
\text { on the chest x-ray }\end{array}$ \\
\hline $\begin{array}{l}\text { A family history of emphysema and/or liver disease, } \\
\text { especially unexplained cirrhosis or hepatoma }\end{array}$ \\
\hline Clinical findings or history of panniculitis \\
\hline $\begin{array}{l}\text { Clinical findings or history of unexplained chronic liver } \\
\text { disease }\end{array}$ \\
\hline
\end{tabular}

Intravenous augmentation via the infusion of pooled human AAT (alpha-1 antiprotease) is currently the most direct and efficient means of elevating AAT levels in the plasma and in the lung interstitium. ${ }^{8}$ In patients with AAT, the augmentation therapy benefit is stronger for individuals with moderate airflow obstruction (e.g., FEV1 35-60\% predicted) than for those with severe airflow obstruction. Augmentation therapy is not currently recommended for individuals without emphysema, and benefits in individuals with severe (e.g., FEV1 $35 \%$ predicted) or mild (e.g., FEV1 50-60\% predicted) airflow obstruction are less clear. ${ }^{1}$ Besides the augmentation therapy cessation of smoking, oxygen therapy, bronchodilators along with gene therapy has been implicated.

\section{CONCLUSION}

The normal alpha- 1 antitrypsin allele is the M allele. Over 100 allelic variants have been described, of which the most common severely deficient variant is the $Z$ allele. Clinical manifestations of severe deficiency of AAT typically involve the lung, liver and rarely the skin. Beyond the first two to three decades of life, patients with severe deficiency of AAT have an accelerated rate of lung function decline, especially with cigarette smoking and some occupational exposures. It is not that the AAT occurs in western part of world but it is under recognised with long intervals between the first symptom and diagnosis.

modifiers of emphysema risk. Thorax 2004; 59(3):259264.

5. Lomas DA, Parfrey H. Alpha(1)-Antitrypsin deficiency: Molecular pathophysiology. Thorax 2004; 59:529.

6. Brantly ML, Paul LD, Miller BH, Falk RT, Wu M, Crystal RG. Clinical features and history of the destructive lung disease associated with alpha-1-antitrypsin deficiency of adults with pulmonary symptoms. Am Rev Respir Dis 1998; 138(2):3278-336.

7. Larsson C. Natural history and life expectancy in severe alpha1-antitrypsin deficiency. Acta Med Scand 1978; 204:345.

8. Stoller JK, Aboussouan LS. Alpha1-Antitrypsin deficiency: intravenous augmentation therapy: current understanding. Thorax 2004; 59:708. 